\title{
The common problem of vectorial optimization in the technological safety management
}

\section{Mykola Chomik A; Yevgen Havrylko ${ }^{\mathrm{B}}$}

Received: January 30, 2020 | Revised: February 28, 2020 | Accepted: February 29, 2020

DOI: $10.33445 /$ sds.2020.10.1.17

\begin{abstract}
In the work examined: possibility of the use of vectorial optimization at a management technogenic safety; some problem aspects of such use; general issue of vectorial optimization at a management technogenic safety and mathematical formalization of this problem comes true.

The marked is caused: by complication and importance of practical problems at military to business, for the decision of that the vehicle of analysis of operations is attracted; by inaccuracy of traditional methods of scalar (onecriterion) optimization at the decision of similar problems; by possibilities of vectorial, multicriterion approach in relation to a search and optimization of administrative decisions at consideration of difficult processes and systems of any nature, including, management technogenic safety.

It is set that basic difficulties of decision of vectorial tasks to optimization of decisions in relation to a management technogenic safety are related to the specification of the initial formalized model, with transformation of her to the kind, comfortable for a choice optimal decision. Thus there is a necessity for the decision of three fundamental problems on that the rightness of optimal choice depends in a great deal: choice of principle of optimality; choice of principle of normalization; choice of principle of taking into account of priority.

Research results can be drawn on during organization of liquidation of consequences of emergencies of different character and realization of management technogenic safety in the aspect of search of optimal decision of such management, including, during the conduct of operation of Incorporated forces.
\end{abstract}

Keywords: management, management efficiency, technogenic safety, vectorial optimization, principle of optimality, model of vectorial optimization, emergency, risk of personnel.

\section{Introduction}

With beginning of the battle operating the new phenomenon - technogenic safety of society during war and her constituent appeared on East of Ukraine - technogenic safety of forces of defensive during the defensive of the state and during removing of aggression. And clear, an important pragmatic problem - management of society technogenic safety appeared during war and management of forces of defensive technogenic safety during the defensive of the state and during removing of aggression, and also at emergencies.
In opinion of author, in the modern raising of decision of the scientifically-applied problem of management technogenic safety no doubt it is straight related to the problems of vectorial (multicriterion) optimization that is actual for the difficult systems of any nature. It is first of all explained by that complication and importance of practical problems extraordinarily grew at military to business for the decision of that, as a rule, the vehicle of analysis of operations is attracted. The traditional methods of scalar (onecriterion) optimization give inexact enough decisions

\footnotetext{
A The National Defense University of Ukraine named after Ivan Cherniakhovskyi, Leading Researcher scientific and organizational department Center for Military Strategic research, Candidate of Technical Science (PhD), Senior Researcher, e-mail: nkhomik@ukr.net, ORCID: 0000-0002-1201-7702

B National Technical University of Ukraine "Igor Sikorsky Kyiv Polytechnic Institute", Ukraine, Department Automation of design of energy processes and systems, Doctor of Engineering Sciences, Professor, e-mail: gev.1964@ukr.net, ORCID: 0000-0001-9437-3964
} 
marked to the circle of problems. Them primitive formalism is unable to manage with numerous difficulties of decision-making at the level of guidance by the difficult organizational systems. Only the vectorial, multicriterion going near the estimation of efficiency and optimization, on persuasion of author, allows to work out high- efficiency scientific methodology of decision of the scientifically-applied problem of management technogenic safety.

In this connection there is a necessity of complex research of question of the use of vectorial optimization at a management technogenic safety.

\section{Analysis of recent research and publications}

To the problem of management technogenic safety, in that, or other the aspects in Ukraine the subzero is devoted works of such well-known scientists: M. Divizinyuk, M. Steblyuk, M. Byichenok, I. Ronanenko, S. Chumachenko, I. Chuba, G. Iyisyichenko, YU. Zabulomov, G. Hmil, O. Zaporogesh, V. Primenko, L. Amjadin, O. Vasyuta, O. Veklich, T. Galushkina, V. Demkin, N. Zinovchuk, V. Kruk, N. Maevska, V. Marinenko, S. Marova, YE. Senyushkin.

However, out of scientific interest of the marked researchers there is a question of the use of vectorial optimization at a management technogenic safety.

It should be noted that general theory of vectorial optimization presently yet distant from the completion and the intensive continues to be developed [1-13], however already up-to-date some theoretical results can be drawn on as an instrument of scientific argumentation made decision at a management technogenic safety.

Basic difficulties of decision of vectorial tasks to optimization are related to the specification of the initial formalized model, with transformation of her to the kind, comfortable for a choice optimal decision. Thus there is a necessity for the decision of three fundamental problems on that the rightness of optimal choice depends in a great deal $[14 ; 15]$.

Firstly, it is a choice of principle of optimality that determines the rule of choice of optimal decision, taking into account the estimation of his quality on all considered criteria. Secondly, it a choice over of principle of normalization, id est such principle that brings all criteria to the only scale of measuring and allows to conduct their comparison. Thirdly, it is a choice of principle of taking into account of priority, that allows to give advantage to more important criteria. These problems carry conceptual character [1-5]. It is very important, that all of them were decided in accordance with character of the real situation of choice of decision of management by technogenic safety.

The resulted confirms actuality and perspective of researches of range of problems of vectorial optimization at a management technogenic safety.

\section{Material and Method}

The purpose of this work is a study of possibility of the use of vectorial optimization at quality of instrument of scientific argumentation made decision at a management technogenic safety, including at application of forces of defensive during the emergencies of natural, technogenic and military character.

\section{Results and discussion}

The modern methods of analysis of operations are appointed to improve quality made decision and find optimal decisions. However, these methods have a serious defect - they are based on supposition, that the estimation of quality and optimization of decisions are conducted on one scalar criterion [6; 7]. Quality of decision of $x$ is estimated by a scalar criterion $y(x)$ and the decision of $x$ gets out as optimal on the multiplicands of possible decisions of $X$ for terms $y\left(x^{\circ}\right)>y(x)^{*}$ for all $x \in X$. Such going near the estimation of efficiency and 
optimization of decisions it is accepted to name scalar or onecriterion, and corresponding to him tasks - by scalar tasks to optimization of decisions.

This class of tasks of optimization is answered by practically all mathematical vehicle of analysis of operations: linear and nonlinear programming, theory of mass service, variation method, game theory, network methods, principle of maximum and other. A like circumstance largely stimulated wide distribution of scalar approach at the decision of practical tasks to optimization and provided wide distribution of this approach during great while.

It is necessary to notice that scalar approach, without regard to mathematical interpretation, first of all characterizes the accepted methodological approach during optimization. He determines that quality of decisions is estimated by one scalar criterion, and on this basis the choice of optimal decision is conducted. Thus absolutely indifferently, as this choice comes true, by means of what mathematical vehicle and what technical equipments $[14 ; 15]$.

In actual fact most practical direction-finding problems have not one, but a few contradictory criteria of efficiency and decision optimal on one of criteria appear unsatisfactory on other criteria. Risks contradict in our case to effective application of personnel. Thus, for the correct choice of optimal decision all criteria must be taken into account.

It is known that multiplicity of criteria is related to the row of important circumstances and has a different origin. However, from the formal point of view nevertheless there is the general going near the choice of decision and general class of tasks of optimization $[7 ; 8 ; 16]$. In the analysis of operations, they got the names of vectorial or multicriterion. The excellent feature of tasks to optimization of this type is that quality of decisions is estimated by means of a few criteria of $y_{1}, y_{2}, \ldots, y_{m}$, that form a vectorial criterion

$$
y=\left(y_{1}, y_{2}, \ldots, y_{\mathrm{m}}\right)
$$

The terms of optimality of decisions are determined on the basis of this vector. The task of vectorial optimization of management technogenic safety in a general view can be set forth thus.

Let $x$ - decision certain on possible multiplicands of decisions X. Quality of decisions is estimated by the local criteria (scalar or vectorial) $y_{1}, y_{2}, \ldots, y_{m}$, what form the vector of efficiency

$$
y=\left(y_{1}, y_{2}, \ldots, y_{m}\right) \text {. }
$$

A vector $y$ is related to the decision-reflection

$$
x \rightarrow y=f(x),
$$

set analytically, statistically or heuristic. Relative importance of local criteria is set by the vector of priority

$$
\lambda=\left(\lambda_{1}, \lambda_{2}, \ldots, \lambda_{m}\right),
$$

where $\lambda_{j} \in[1, \infty]$ - binary relation of priority of criterion of $\boldsymbol{j}$ above a criterion $(j+1)$.

It is necessary to find the optimal decision of $x$ (management technogenic safety), that is determined by two terms:

a decision must be it is carried out, id est to belong multiplicands of possible decisions of $X$;

a decision must be the best, id est to optimize the vector of efficiency $y$ taking into account priority of criteria.

This formulation is answered by the model of vectorial optimization of kind

$$
x^{0}=f^{-1}[\operatorname{opt}(\underset{x \in X}{(y(x), \lambda)] .}
$$

In our case maybe unonly optimal decision, when as optimal the optimal subset of decisions $X^{0}$ and task is distinguished acquires a kind

$$
\left.X^{0}=\left\{x^{0}\right\}=\bigcup_{x \in X} f^{-1}[\operatorname{opt} \underset{x \in X}{(x(x)}, \lambda)\right]
$$

where: opt - operator of optimization that determines principle of optimality and makes sense ordering relations; $f^{-1}$ - retroreflection $x \rightarrow y=f(x)$. The marked model is the model of vectorial optimization. In her a criterion over of quality (or to efficiency) vector $y$ and her realization bring to being of optimal decision $x^{0}$ or optimal subset $X^{0}$.

This model is isomorphic enough formal generalization of task to the choice of optimal 
decision. By the partial case of that at $m=1$ (when $y$-scalar) there is a scalar (onecriterion) task of optimization. In general case for similar tasks the choice of optimal decision can be carried out analytically or heuristic, "by" hand or with the use of computer.

In the aspect of the use of vectorial optimization at the decision of problem of efficiency of management technogenic safety mathematical formalization of the marked problem appears an important element.

Will consider the task of management technogenic safety. Let exist:

1) great number of consequences of emergencies

$$
\left\|w_{j}\right\|=\Omega
$$

where $w_{j}-$ vector $(j \in N)$, that in full characterizes the consequence $j$ of emergencies (to the plane, sentinels and other descriptions of emergencies) is;

2) great numbers of subdivisions of troops (forces) of 3CУ and other forming are for liquidation of consequences of emergencies

$$
\left\|p_{i}\right\|=P,
$$

here $p_{i}$ - vector $(i \in N)$, that characterizes subdivision (full strength, train and other);

3) efficiency of the job processing of subdivisions $i$ of troops (forces) of forces of defensive are at liquidation of consequences $j$ of emergencies during a management technogenic safety $-E_{J P_{i j}}$;

4) a risk of the job processing of subdivisions $i$ of troops (forces) of forces of defensive are at liquidation of consequences $j$ of emergencies during a management technogenic safety $-R_{i j}$;

5) matrix of dynamic allocation of resources, that the actual is the plan of implementation of tasks by subdivisions of troops (forces) of forces of defensive at liquidation of consequences of emergencies (matrix of management technogenic safety)

$$
X(t)=\left|\begin{array}{cccc}
x_{11}(t) & x_{12}(t) & \ldots & x_{1 i}(t) \\
x_{21}(t) & x_{22}(t) & \ldots & x_{2 i}(t) \\
x_{31}(t) & x_{32}(t) & \ldots & x_{3 i}(t) \\
\ldots & \ldots & \ldots & \ldots \\
x_{j 1}(t) & x_{j 2}(t) & \ldots & x_{j i}(t)
\end{array}\right|
$$

6) efficiency of management technogenic safety $-W_{T S}$.

Formalization of task of search of management technogenic safety looks like ( $t-$ time)

$$
X^{0}(t):\left\{\begin{array}{l}
R_{i j} \rightarrow \min , \\
E_{J P i j} \rightarrow \max \\
W_{T S} \rightarrow \max , \\
|P| \rightarrow \text { min. }\{
\end{array} \quad(i, j \in N),\right.
$$

Taking into account denotations of components of vector $y\left(R_{i j}, E_{J P i j}, W_{T S}, P\right)$ and formulas (2), expression (1) expedient to write down

$$
X^{0}(t)=\left\{x_{i j}^{0}(t)\right\}=\underset{x \in X}{\cup} f^{-1}\left[\operatorname{opt}\left(\left[R_{i j}, E_{J P i j}, W_{T S}, P\right], \lambda\right)\right],
$$

But ordinary logic gives the following

$$
\left\{\begin{array}{l}
R_{i j} \rightarrow \min \Rightarrow \overline{E_{J P i j} \rightarrow \max ,} \\
E_{J P i j} \rightarrow \max \Rightarrow \overline{R_{i j} \rightarrow \min } \\
W_{T S} \rightarrow \max \Rightarrow \overline{|P| \rightarrow \min } \\
|P| \rightarrow \min \Rightarrow \overline{W_{T S} \rightarrow \max }\{
\end{array}\right.
$$

We see that certain contradictions are between requirements in relation to efficiency of implementation of tasks by forces of defensive, by the risks of personnel during implementation of these tasks, by a management technogenic safety, quality description of subdivisions of troops (forces) of forces of defensive. The marked contradictions just and are essence of theoretical problem of vectorial optimization at a management technogenic safety common expression of that is presented on fig. 


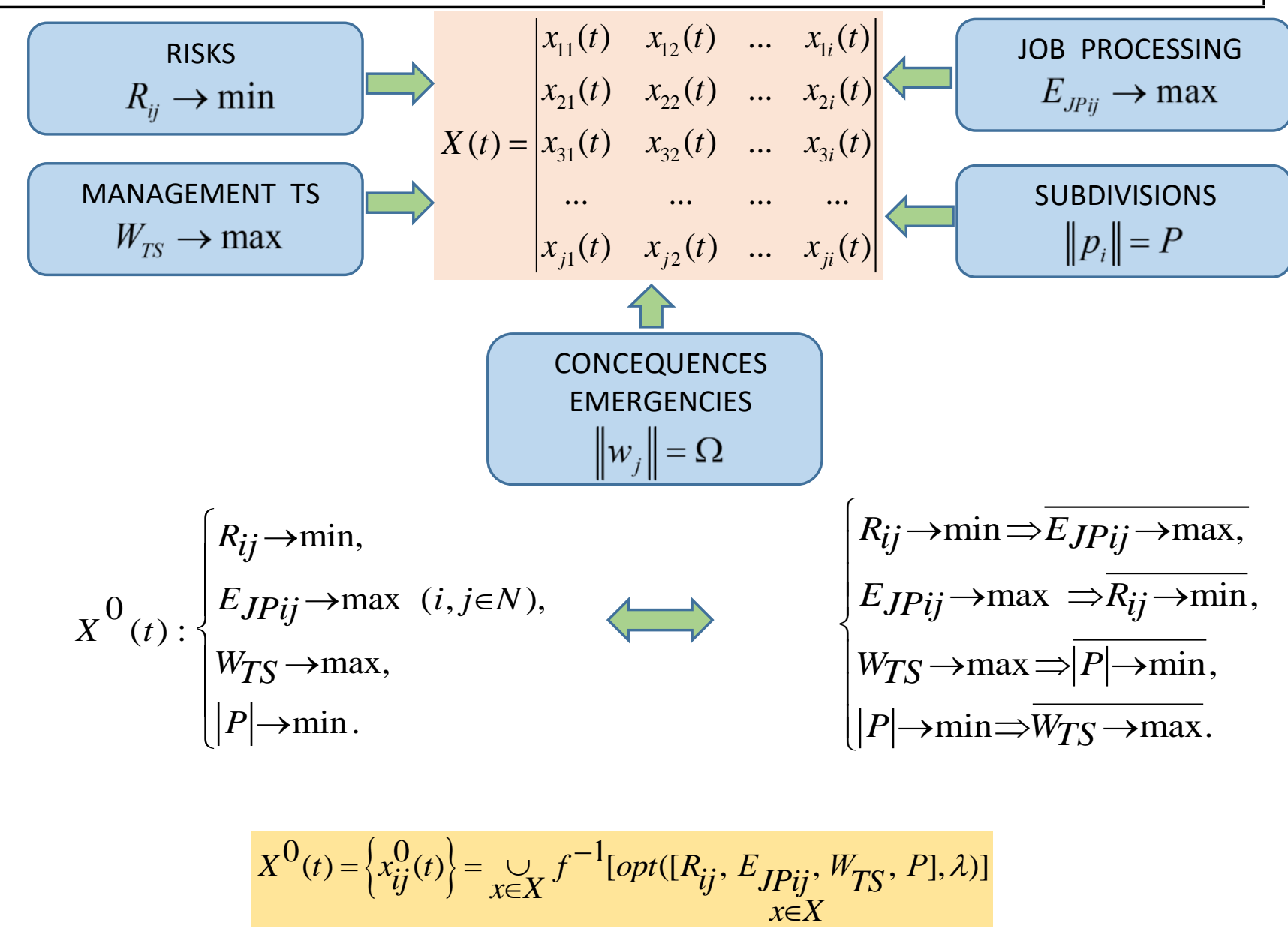

Fig. - Common expression of theoretical problem of vectorial optimization is at a management technogenic safety

\section{Conclusions}

It is well-proven that theoretical features of decision of scientifically-applied problem of management technogenic safety on present tense related to the problems of vectorial or multicriterion optimization that is actual for the difficult systems of any nature. It is explained by that complication and importance of practical problems extraordinarily grew at military to business for the decision of that the vehicle of analysis of operations is attracted. The traditional methods of scalar (onecriterion) optimization are inexact enough for the decision of similar problems. Them the simplified approaches are unable to manage with the great number of decision-making difficulties at the level of guidance by the difficult organizational systems. Only the vectorial, multicriterion going near the estimation of efficiency and optimization the scientific tool of decision of problem of management technogenic safety will allow to work out.

General theory of vectorial optimization presently yet distant from the completion and the intensive continues to be developed. However already up-to-date some theoretical results can be drawn on as an instrument of scientific argumentation made decision at a management technogenic safety.

\section{References}

1. Abramov O.V., Rosenbaum, A.N. Forecasting the State of Technical Systems. Moscow: Science, 1990. $126 \mathrm{p}$.
2. Abramov O.V. Monitoring and forecasting of technical condition of responsible systems. 
Reliability and quality of complex systems. 2018. № 4 (24). P. 108-115.

3. Bellman R. Zade L. Making Decisions in Vague Conditions: A Collection of Translations. Moscow: World, 1976. P. 172-215.

4. Belov of P. G. Zaporozhchenko Yu. F. Sushchnost and methods of forecasting of technogenic risk. Messenger of a kmug. 1999. No1. P. 260-264.

5. Benkovich E.S. Kolesov Yu. B., Senichenkov Yu. B. Practical modeling of dynamic systems: manual. St. Petersburg, 2002. 464 p.

6. Buslenko N.P., Kalashnikov V.V., Kovalenko I.N. Lectures on the theory of complex systems. Moscow: Soviet Radio, 1973. 440 p.

7. Ventzel E.S. Operations Study. Moscow: Soviet Radio, 1972. 552 p.

8. Vyichujanin V.V., Rudchenko N.D. Technical risks of complex complexes of functionally interconnected structural components of ship power plants. V_snik Odeskogo nats_onalny sea to an un_versitet. 2014. № 2. P.68-77.

9. Gorban II Probability Theory and Mathematical Statistics for Scientists and Engineers. Kyiv: NANU. IPMMS. 2003. 244 p.

10. Dubois D., Prad A. Theory of Opportunity. Applications to the presentation of knowledge in computer science. Moscow, 1990. 286 p.

11. Zaychenko Yu. P. Fuzzy models and methods in intellectual systems: educational manual for students of higher educational institutions. Kiev: Word, 2008. 344 p.

12. Modeling and optimization of information systems: a textbook / Kravchenko YV and others. Kyiv: DUT, 2019, 312 p.

13. Sustainable development of inland waterway transport in China (2009). Theme I of a World Bank Project: Comprehensive Transport System Analysis in China URL: http://siteresources.world bank.org/EXTPRAL/Resources/china.pdf (date of appeal 02.01.2020).

14. Yager, R. and D. Filev, "Generation of Fuzzy Rules by Mountain Clustering," Journal of Intelligent \& Fuzzy Systems, 1994, Vol. 2, No. 3, P. 209-219.

15. Lisowski J. Game control methods in navigator decision support system / The Archives of Transport. 2005. No 3-4, Vol. XVII. P. $133-147$.

16. Reform in the inland water transport: China's experience URL: https://www. unescap.org/our-work/ transport (date of appeal 12.12.2019). 